\title{
Effect of glycemic control on plasma oxidized low density lipoprotein levels in diabetics
}

\author{
Koichi Ono \\ Department of Internal Medicine, Innoshima Medical Associated Hospital, Onomichi, Japan
}

Email address:

ishikai@beach.ocn.ne.jp

To cite this article:

Koichi Ono. Effect of Glycemic Control on Plasma Oxidized Low Density Lipoprotein Levels in Diabetics. Science Journal of Clinical Medicine. Vol. 3, No. 5, 2014, pp. 91-97. doi: 10.11648/j.sjcm.20140305.13

\begin{abstract}
Objective: Increased low-density lipoprotein (LDL) glycation in diabetics could facilitate LDL oxidation, which is proatherogenic. I studied plasma oxidized LDL (OxLDL) levels in diabetics and non-diabetics, their relation to glycemic control, and their circadian variations. Methods: OxLDL in diabetics $(\mathrm{n}=32)$ and in non-diabetics without coronary artery diseases $(n=20)$ were compared. OxLDL in diabetics $(n=24)$ was measured on Days $2,3,4,8$ and the last day of hospitalization. Circadian variation in OxLDL in diabetics $(\mathrm{n}=18)$ was also examined. Glycemic control was implemented during hospitalization. Patients: The diabetics were divided into two groups; moderately-controlled (MC) group (HbAlc $<$ $9.0 \%$ at admission, $\mathrm{n}=15$ ) and poorly-controlled $(\mathrm{PC})$ group (HbAlc $\geqq 9.0 \%$ at admission, $\mathrm{n}=9$ ). Results: In the MC group, OxLDL decreased by $20.8 \%$ after glycemic control $(\mathrm{p}=0.0139)$, but not in the PC group. OxLDL is correlated with LDL on Days 3, 4, $8(\mathrm{r}=0.837,0.864,0.801$, respectively), TG on Day $8(\mathrm{r}=0.932)$, and $\mathrm{Lp}(\mathrm{a})$ at discharge $(\mathrm{r}=0.871)$. In the PC group, OxLDL was $15.8 \%$ higher on the average in the daytime than at night $(\mathrm{p}=0.0024)$. Conclusion: Plasma OxLDL is decreased by glycemic control, particularly in moderately glycemic controlled patients. OxLDL has a circadian variation, particularly in poorly glycemic controlled patients. Long-term glycemic control could reduce the progression of atherosclerosis, by reducing OxLDL levels.
\end{abstract}

Keywords: Diabetes Mellitus, Oxidized LDL, Circadian Variation

\section{Introduction}

There is a well-established association of diabetes mellitus with the development of atherosclerosis. Recent prospective data have clearly established a link between a marker for chronic average glucose levels, hemoglobin A1c (HbA1c) and cardiovascular morbidity and mortality $[1,2$, 3]. Diabetes mellitus is associated with enhanced low-density lipoprotein (LDL) glycosylation [4] and glycated LDL is considered to be oxidized more easily than intact LDL [5, 6, 7, 8]. Oxidized low-density lipoprotein (OxLDL) is a powerful natural prooxidant derived in vivo from native LDL by cell-mediated oxidation [9]. OxLDL is a key proatherogenic agent [10] that induces an increase in Reactive Oxygen Species (ROS) formation, specific alterations in gene/protein expression, and apoptosis of vascular smooth muscle cells $[11,12,13,14]$. It was unclear (a) whether plasma oxidized LDL levels in diabetics were improved with temporary glycemic control, (b) whether these changes occurred subsequent to temporary glycemic control during hospitalization and (c) whether there was circadian variation in plasma OxLDL levels. This study was conducted to compare plasma OxLDL in diabetic and non-diabetic patients, to determine effects of temporary glycemic control during hospitalization on OxLDL levels, and to examine circadian rhythm in OxLDL levels.

\section{Materials and Methods}

\subsection{Study Patients}

The study included 32 consecutive diabetic patients [type 1 diabetes $(\mathrm{n}=2)$ and type 2 diabetes $(\mathrm{n}=30)]$ and 20 consecutive non-diabetic patients with normal coronary angiograms. The diabetic patients entered Hiroshima University Medical Hospital and affiliated hospitals for temporary glycemic control between November 1997 and February 1998. The non-diabetic patients underwent cardiac catheterization in Hiroshima University Medical Hospital and affiliated hospitals between October 1997 and February 1998 because of suspicious angina pectoris. 
OxLDL in diabetics on Day 2 was compared to OxLDL in non-diabetics without coronary artery disease on the day of cardiac catheterization. Of the 32 diabetic patients, 24 were observed for more than eight days in Hiroshima University Medical Hospital and their OxLDL was measured on Days 2, $3,4,8$ and the last day of hospitalization (median day 15, mean day 20.8). HbA1c values were used by the Japan Diabetes Society (JDS) HbA1c numbers. The 24 diabetics were divided into two groups; (a) moderately-controlled (MC) group (HbA1c $<9.0 \%$ (JDS) at admission, $\mathrm{n}=15)$ and (b) poorly-controlled (PC) group (HbAlc $\geqq 9.0 \%$ (JDS) at admission, $n=9$ ). Their medication was not changed except for glycemic control during hospitalization.

Of the 24 diabetic patients in Hiroshima University Medical Hospital, 18 agreed to participate in the study of circadian variation in OxLDL. Their blood samples were taken at 8:00 am, 10:00 am, 11:30 am, 5:30 pm, midnight and 5:00 am. The 18 diabetics were also divided into two groups and examined; (a) moderately-controlled (MC) group (HbA1c $<9.0 \%$ (JDS) at admission, $\mathrm{n}=10$ ), (b) poorly-controlled (PC) group (HbAlc $\geqq 9.0 \%$ (JDS) at admission, $\mathrm{n}=8$ ).

Exclusion criteria were: (a) patients receiving antioxidant drugs or who smoked and (b) patients with variant angina, previous myocardial infarction, congestive heart failure, cardiomyopathy, valvular heart disease, stroke, cancer, or other debilitating disease. Informed consent was obtained from all patients before the study. The study conformed to the principles outlined in the Declaration of Helsinki [15] and the protocol was approved by the ethics committee of the department of Internal Medicine II in Hiroshima University Medical Hospital.

\subsection{Blood Samples}

Venous blood was taken from all of the study patients after an overnight fast except when samples were obtained for study of circadian variation. Blood samples, anticoagulated with EDTA, were immediately centrifuged at $3000 \mathrm{rpm}$ at 4 degrees Celsius for $10 \mathrm{~min}$ and stored at 4 degrees Celsius. The OxLDL levels of plasma samples were assessed within 14 days after blood drawing as reported previously [16]. Plasma OxLDL level was measured by sandwich ELISA using DLH3, an anti-oxidized phosphatidylcholine monoclonal antibody and an anti-apolipoprotein B antibody as previously described [17]. One unit was defined as equivalent to $250 \mathrm{ng}$ of copper-oxidized LDL [18]. We also examined the followings: (a) on Day 2 and the last hospital day; Total cholesterol (T-cho), Triglyceride (TG), High-density lipoprotein (HDL) cholesterol, Low-density lipoprotein (LDL) cholesterol, Creatine phosphokinase (CPK), Creatine kinase isoenzyme 2 or Creatine kinase isoenzyme MB (CK-MB), Complete blood cell count (CBC), apolipoprotein A-1 (apo-A1), apolipoprotein B (apo-B), Lipoprotein (a) (Lp(a)), fasting blood sugar (FBS), HbAlc, glycated albumin, and 1,5-anhydroglucitol (1,5-AG), and (b) on Days 3, 4 and 8; T-cho, TG, HDL cholesterol, LDL cholesterol, and FBS.

\subsection{Statistical Analysis}

Values are expressed as percentages, means $\pm \mathrm{SD}$ or means \pm SE. In case the data were normally distributed, the two groups were compared with an unpaired $t$ test; otherwise, a Mann-Whitney U test was used. Statistical comparisons between more than three groups like data relating to circadian variation of OxLDL were performed by 1-way ANOVA and post hoc multiple comparison with Scheffé's test. P values of less than 0.05 were considered to indicate statistical significance.

\section{Results}

\subsection{Patient Characteristics between Diabetics and Non-Diabetics}

Clinical characteristics are shown in Table 1. The diabetic group was well matched for age and sex with the non-diabetic group. The patients with diabetes had significantly elevated levels of fasting blood glucose and HbA1c. OxLDL was higher in the diabetic $(8.90 \pm 5.07$ $\mathrm{U} / \mathrm{ml})$ than non-diabetic group $(6.93 \pm 2.12 \mathrm{U} / \mathrm{ml})$, but it did not reach statistical significance $(\mathrm{p}=0.1048)$.

Table 1. Patient characteristics

\begin{tabular}{|c|c|c|c|c|}
\hline & Unit & Diabetic subjects $(n=32)$ & Non-diabetic subjects $(n=20)$ & P value \\
\hline Age & (yr.) & $58.5 \pm 15.1$ & $59.5 \pm 10.9$ & NS \\
\hline Males & $(\%)$ & 59 & 50 & NS \\
\hline Total cholesterol & $(\mathrm{mg} / \mathrm{dl})$ & $239.2 \pm 129.6$ & $202.6 \pm 41.3$ & NS \\
\hline Triglyceride & $(\mathrm{mg} / \mathrm{dl})$ & $169.1 \pm 114.2$ & $120.4 \pm 52.6$ & 0.08 \\
\hline HDL cholesterol & $(\mathrm{mg} / \mathrm{dl})$ & $50.5 \pm 14.4$ & $54.3 \pm 17.3$ & NS \\
\hline LDL cholesterol & $(\mathrm{mg} / \mathrm{dl})$ & $153.4 \pm 114.7$ & $128.7 \pm 34.5$ & NS \\
\hline OxLDL & (Unit/ml) & $8.9 \pm 5.1$ & $6.9 \pm 2.1$ & 0.10 \\
\hline $\mathrm{Lp}(\mathrm{a})$ & $(\mathrm{mg} / \mathrm{dl})$ & $42.7 \pm 61.9$ & $20.4 \pm 13.1$ & NS \\
\hline Apo A-1 & $(\mathrm{mg} / \mathrm{dl})$ & $130.8 \pm 28.3$ & $138.8 \pm 25.3$ & NS \\
\hline Apo B & $(\mathrm{mg} / \mathrm{dl})$ & $129.3 \pm 93.0$ & $96.4 \pm 30.2$ & NS \\
\hline FBS & $(\mathrm{mg} / \mathrm{dl})$ & $153.3 \pm 50.8$ & $94.9 \pm 11.8$ & 0.0001 \\
\hline HbA1c (JDS) & $(\%)$ & 8.6 & 5.1 & 0.0001 \\
\hline
\end{tabular}




\subsection{Plasma OxLDL Levels in 24 Diabetic Patients}

As shown in Figure 1, OxLDL decreased by $13.1 \%$ from Day 2 to the last hospital day $(\mathrm{p}=0.192)$. I also investigated
OxLDL levels of the MC group and the PC group, separately. The mean duration from admission to discharge was 21 days.

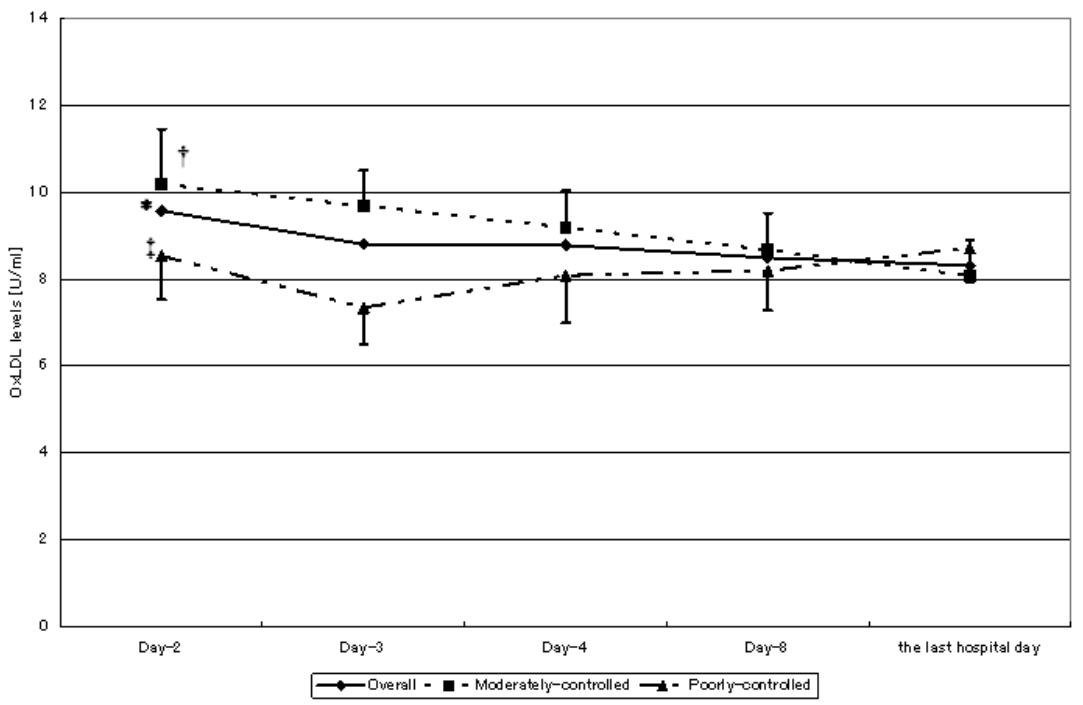

Figure 1. Shows plasma OxLDL changes in diabetic subjects during hospitalization.

* Plasma OxLDL levels on Day 2 versus the last hospital day in overall $(\mathrm{p}=0.192)$.

$\uparrow$ Plasma OxLDL levels on the last hospital day showed 20.8\% reduction compared with those on Day 2 in moderately-controlled group $(p=0.0139)$.

$\$$ Plasma OxLDL levels on the last hospital day showed 2.2\% increase compared with those on Day 2 in poorly-controlled group (p=NS).

Data are expressed as mean $\pm \mathrm{SE}$

\subsection{Diabetic Patient Characteristics on Day 2 and the Last}

\section{Hospital Day}

Table 2. Patient characteristics between the moderately-controlled group and the poorly-controlled group

\begin{tabular}{|c|c|c|c|c|}
\hline & Unit & Modelately-controlled $(n=15)$ & Poorly-controlled (n = 9) & Pvalue \\
\hline Age & (yr.) & $62.5 \pm 14.3$ & $50.1 \pm 17.3$ & NS \\
\hline Males & $(\%)$ & 66.7 & 53.3 & NS \\
\hline Mean duration & (days) & 24.7 & 18.4 & NS \\
\hline $\begin{array}{l}\text { Antihyperlipidemic agents } \\
\text { on Day } 2\end{array}$ & $(\%)$ & 33.3 & 22.2 & NS \\
\hline Total cholesterol & $(\mathrm{mg} / \mathrm{dl})$ & $207.8 \pm 47.1$ & $232.3 \pm 62.2$ & NS \\
\hline Triglyceride & $(\mathrm{mg} / \mathrm{dl})$ & $135.9 \pm 87.1$ & $169.0 \pm 117.0$ & NS \\
\hline HDL cholesterol & $(\mathrm{mg} / \mathrm{dl})$ & $51.5 \pm 11.2$ & $48.2 \pm 18.5$ & NS \\
\hline LDL cholesterol & $(\mathrm{mg} / \mathrm{dl})$ & $116.1 \pm 36.3$ & $146.8 \pm 53.2$ & NS \\
\hline FBS & $(\mathrm{mg} / \mathrm{dl})$ & $122.7 \pm 27.5$ & $162.2 \pm 33.2$ & 0.06 \\
\hline HbAlc (JDS) & $(\%)$ & 7.32 & 10.7 & 0.0001 \\
\hline $1,5-\mathrm{AG}$ & $(\mathrm{mg} / \mathrm{dl})$ & $6.77 \pm 6.8$ & $1.4 \pm 0.5$ & 0.02 \\
\hline glycated albumin & $(\mathrm{mg} / \mathrm{dl})$ & $23.1 \pm 2.9$ & $34.6 \pm 7.2$ & 0.0001 \\
\hline $\mathrm{Lp}(\mathrm{a})$ & $(\mathrm{mg} / \mathrm{dl})$ & $40.5 \pm 43.8$ & $28.8 \pm 29.8$ & NS \\
\hline Apo A-1 & $(\mathrm{mg} / \mathrm{dl})$ & $128.9 \pm 22.0$ & $119.7 \pm 20.0$ & NS \\
\hline $\begin{array}{l}\text { Apo B } \\
\text { on the last hospital day }\end{array}$ & $(\mathrm{mg} / \mathrm{dl})$ & $110.8 \pm 33.9$ & $125.8 \pm 34.3$ & NS \\
\hline Total cholesterol & $(\mathrm{mg} / \mathrm{dl})$ & $195.9 \pm 38.0$ & $202.1 \pm 42.8$ & NS \\
\hline Triglyceride & $(\mathrm{mg} / \mathrm{dl})$ & $127.9 \pm 81.3$ & $118.7 \pm 62.2$ & NS \\
\hline HDL cholesterol & $(\mathrm{mg} / \mathrm{dl})$ & $51.5 \pm 11.2$ & $48.2 \pm 18.5$ & NS \\
\hline LDL cholesterol & $(\mathrm{mg} / \mathrm{dl})$ & $116.1 \pm 36.3$ & $127.7 \pm 29.2$ & NS \\
\hline FBS & $(\mathrm{mg} / \mathrm{dl})$ & $101.2 \pm 9.4$ & $117.3 \pm 28.3$ & NS \\
\hline HbAlc (JDS) & $(\%)$ & 7.13 & 9.37 & 0.0001 \\
\hline $1,5-\mathrm{AG}$ & $(\mathrm{mg} / \mathrm{dl})$ & $7.47 \pm 6.22$ & $3.94 \pm 1.57$ & NS \\
\hline glycated albumin & $(\mathrm{mg} / \mathrm{dl})$ & $22.2 \pm 4.0$ & $28.3 \pm 4.7$ & 0.0025 \\
\hline Lp(a) & (mg/dl) & $40.5 \pm 48.1$ & $24.8 \pm 15.0$ & NS \\
\hline Apo A-1 & $(\mathrm{mg} / \mathrm{dl})$ & $123.1 \pm 12.1$ & $115.7 \pm 28.2$ & NS \\
\hline Apo B & $(\mathrm{mg} / \mathrm{dl})$ & $102.0 \pm 31.1$ & $106.1 \pm 25.2$ & NS \\
\hline
\end{tabular}

Values are percentages or means $\pm \mathrm{SD}$. 
Clinical characteristics are shown in Table 2. On Day 2, the PC group had significantly elevated levels of HbA1c (1.46 fold higher than $\mathrm{MC}$ ) and glycated albumin (1.50 fold higher than MC) and had decreased levels of 1,5-AG (4.8 fold lower than MC). On the last hospital day, the PC group had significantly elevated levels of HbAlc (1.31 fold higher than MC) and glycated albumin (1.27 fold higher than MC). Although there was a statistically significant difference in plasma fasting blood sugar at the beginning of hospitalization (1.51 fold higher in PC compared with MC on Day 2), these differences were lost in one week after $[134.2 \pm 34.5 \mathrm{mg} / \mathrm{dl}$ (MC) versus $152.7 \pm 38.7 \mathrm{mg} / \mathrm{dl}(\mathrm{PC}), \mathrm{p}=\mathrm{NS}]$, and at the time of leaving hospital.

\subsection{Plasma OxLDL Levels in Moderately-Controlled and Poorly-Controlled Patients}

Figure 1 shows that in the MC group there was a $20.8 \%$ reduction in OxLDL after glycemic control $(p=0.0139)$ in spite of no significant change in total cholesterol levels (Table 2). In contrast, there was no significant decrease in OxLDL during the hospitalization in the $\mathrm{PC}$ group in spite of a significant $27.4 \%$ decrease in total cholesterol levels ( $\mathrm{p}=$ $0.034)$.

\subsection{Correlation with Plasma OxLDL Levels and other Indexes}

OxLDL is strongly correlated with LDL cholesterol on Day 3, 4, 8 ( $\mathrm{r}=0.837,0.864,0.801$, respectively), TG on Day $8(\mathrm{r}=0.932)$, and $\mathrm{Lp}(\mathrm{a})$ at discharge $(\mathrm{r}=0.871)$.

\subsection{Circadian Rhythm of Plasma OxLDL}

To examine the circadian variation in OxLDL, 18 diabetic patients participated in plasma sample collection at the indicated time points (Figure 2). Clinical characteristics are shown in Table 3. As a whole, the OxLDL level increased in the morning, but it was not statistically significant. To determine whether the hyperglycemic status had an impact on the circadian variation in OxLDL, I also investigated OxLDL levels of the MC group and PC group, separately. In the MC group, OxLDL levels were unchanged over 24 hours. However, in the PC group, OxLDL levels were changed from $9.26 \pm 1.23 \mathrm{U} / \mathrm{ml}$ at $8: 00$ am to $6.53 \pm 1.12 \mathrm{U} / \mathrm{ml}$ at midnight and were significantly lower during the night than during the day $(\mathrm{p}=0.0024)$. The average levels of OxLDL during the day were $15.8 \%$ higher than levels at midnight and $5 \mathrm{am}$.

Table 3. Patient characteristics of the circadian variation participants between the moderately-controlled group and the poorly-controlled group

\begin{tabular}{|c|c|c|c|c|}
\hline & Unit & Modelately-controlled $(\mathrm{n}=10)$ & Poorly-controlled $(\mathrm{n}=8)$ & P value \\
\hline Age & (yr.) & $61.9 \pm 14.0$ & $47.0 \pm 16.7$ & 0.07 \\
\hline Males & $(\%)$ & 45.5 & 57.1 & NS \\
\hline Mean duration & (days) & 16.0 & 28.2 & NS \\
\hline $\begin{array}{l}\text { Antihyperlipidemic agents } \\
\text { on Day } 2\end{array}$ & $(\%)$ & 45.5 & 28.6 & NS \\
\hline Total cholesterol & $(\mathrm{mg} / \mathrm{dl})$ & $220.2 \pm 40.2$ & $246.4 \pm 57.9$ & NS \\
\hline Triglyceride & $(\mathrm{mg} / \mathrm{dl})$ & $131.3 \pm 67.1$ & $187.3 \pm 118.8$ & NS \\
\hline HDL cholesterol & $(\mathrm{mg} / \mathrm{dl})$ & $58.0 \pm 16.0$ & $49.7 \pm 15.7$ & NS \\
\hline LDL cholesterol & $(\mathrm{mg} / \mathrm{dl})$ & $135.6 \pm 38.6$ & $154.4 \pm 52.4$ & NS \\
\hline FBS & $(\mathrm{mg} / \mathrm{dl})$ & $135.0 \pm 20.7$ & $157.8 \pm 31.7$ & NS \\
\hline HbA1c (JDS) & $(\%)$ & 7.55 & 11.0 & 0.0001 \\
\hline $1,5-\mathrm{AG}$ & $(\mathrm{mg} / \mathrm{dl})$ & $4.06 \pm 3.5$ & $1.23 \pm 0.2$ & 0.06 \\
\hline glycated albumin & $(\mathrm{mg} / \mathrm{dl})$ & $22.6 \pm 3.1$ & $35.4 \pm 7.5$ & 0.0002 \\
\hline $\mathrm{Lp}(\mathrm{a})$ & $(\mathrm{mg} / \mathrm{dl})$ & $45.5 \pm 47.9$ & $31.0 \pm 30.1$ & NS \\
\hline Apo A-1 & $(\mathrm{mg} / \mathrm{dl})$ & $137.4 \pm 17.8$ & $119.4 \pm 21.1$ & 0.09 \\
\hline $\begin{array}{l}\text { Apo B } \\
\text { on the last hospital day }\end{array}$ & $(\mathrm{mg} / \mathrm{dl})$ & $116.6 \pm 32.1$ & $133.9 \pm 29.5$ & NS \\
\hline Total cholesterol & $(\mathrm{mg} / \mathrm{dl})$ & $196.8 \pm 35.5$ & $212.1 \pm 38.7$ & NS \\
\hline Triglyceride & $(\mathrm{mg} / \mathrm{dl})$ & $118.3 \pm 51.2$ & $126.0 \pm 64.4$ & NS \\
\hline HDL cholesterol & $(\mathrm{mg} / \mathrm{dl})$ & $50.9 \pm 9.0$ & $51.1 \pm 18.7$ & NS \\
\hline LDL cholesterol & $(\mathrm{mg} / \mathrm{dl})$ & $120.7 \pm 36.3$ & $131.7 \pm 28.3$ & NS \\
\hline FBS & $(\mathrm{mg} / \mathrm{dl})$ & $101.5 \pm 9.4$ & $117.3 \pm 23.1$ & NS \\
\hline HbA1c (JDS) & $(\%)$ & 7.27 & 9.34 & 0.0003 \\
\hline $1,5-\mathrm{AG}$ & $(\mathrm{mg} / \mathrm{dl})$ & $5.85 \pm 3.8$ & $4.01 \pm 1.65$ & NS \\
\hline glycated albumin & $(\mathrm{mg} / \mathrm{dl})$ & $20.9 \pm 2.5$ & $28.1 \pm 4.7$ & 0.0012 \\
\hline $\mathrm{Lp}(\mathrm{a})$ & $(\mathrm{mg} / \mathrm{dl})$ & $48.2 \pm 52.0$ & $25.6 \pm 12.3$ & NS \\
\hline Apo A-1 & $(\mathrm{mg} / \mathrm{dl})$ & $123.1 \pm 12.3$ & $120.1 \pm 28.4$ & NS \\
\hline Apo B & $(\mathrm{mg} / \mathrm{dl})$ & $104.9 \pm 30.0$ & $109.7 \pm 24.8$ & NS \\
\hline
\end{tabular}

Values are percentages or means $\pm \mathrm{SD}$. 


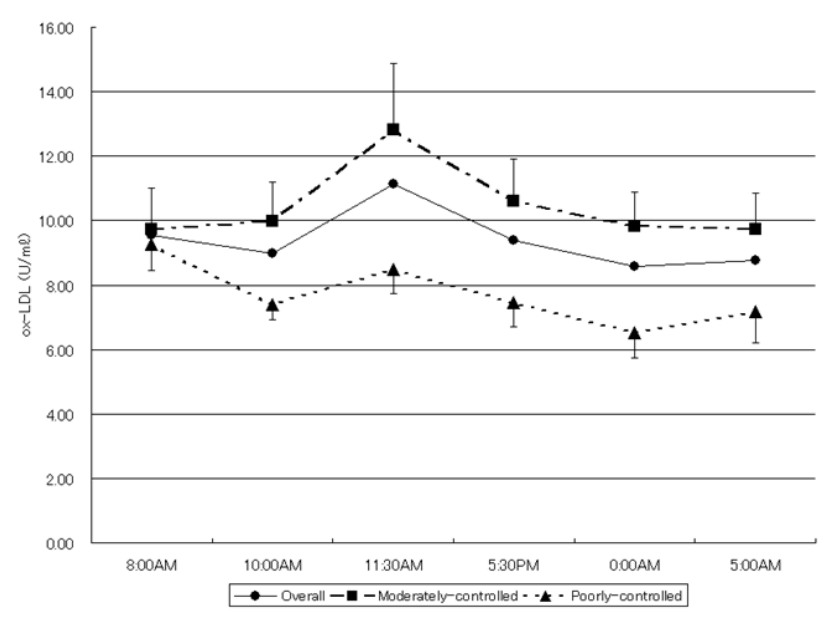

Figure 2. shows circadian variation in plasma OxLDL levels in diabetics

Circadian variation in the poorly-controlled group showed statistically significant difference by ANOVA $(\mathrm{p}=0.0024)$. Data are expressed as mean $\pm \mathrm{SE}$

\section{Discussion}

This study shows that plasma OxLDL levels were $28 \%$ higher in the diabetic group compared to the control group, although this did not reach statistical significance, possibly in partly due to the sample size. Toshima et al. showed OxLDL levels were significantly higher in diabetic patients $(\mathrm{n}=102)$ than in control patients $(\mathrm{n}=181)(\mathrm{p}<0.01)[16]$. This finding needs to be validated in more patients. The difference in plasma OxLDL levels between the MC and PC groups was not significantly different.

I found that plasma OxLDL levels in MC group (i.e. those with $\mathrm{HbAlc}<9 \%$ at admission) decreased after temporary glycemic control during hospitalization, whereas plasma OxLDL levels in the PC group were unchanged during the hospitalization in spite of a reduction in total cholesterol levels. The increased serum glycated LDL level in diabetic patients correlates with their parameters of glycemic control [19] and glycated LDL is said to be more easily oxidized than native LDL [7]. Thus the unchanged plasma OxLDL levels in PC group could be related to higher glycated LDL levels. It has been shown that eight-week glycemic control resulted in a significant reduction in serum lipid peroxidases, as an accepted index of intravascular free radicals, when glycated HbA1c dropped to under 7\% [20]. In another study of 21 type 2 diabetes in who require insulin therapy to control metabolism, there was no change in lipid peroxidation in spite of a significant decrease in HbA1c from $10.6 \pm 1.1 \%$ to $7.9 \pm 0.6 \%$ [21]. In this study, HbA1c levels in $\mathrm{MC}$ group dropped from $7.32 \%$ to $7.13 \%$, and OxLDL levels in these patients also decreased significantly. In PC group, OxLDL levels did not change significantly in spite of the HbAlc improvement $(10.7 \%$ to $9.37 \%)$. However, there was no correlation between plasma OxLDL and $\mathrm{HbA} 1 \mathrm{c}$ levels in diabetic patients. Moreover, in diabetic patients, there was no relationship between plasma OxLDL levels and serum fasting and postprandial blood sugar levels. Toshima et al. also found the same results [16].

Several factors may contribute to LDL peroxidation. Intense, long duration aerobic exercise increases LDL susceptibility to oxidation [22]. A 10-month exercise program reduces oxidized LDL levels [23]. E-series prostaglandins may significantly inhibit copper-induced oxidation of native LDL [24]. Nicotine destabilizes the production of hydroperoxides in LDL and increases the formation of secondary oxidation products [25]. Hypertension and hyperlipidemia are also promoters of oxidation [26, 27]. This study shows that controlling blood glucose levels may reduce LDL oxidation. In the MC group, there was a significant $13.3 \%$ reduction in OxLDL after glycemic control, which could lower glycated LDL and hence suppress LDL oxidation. On the other hand, regardless of better glycemic control, plasma OxLDL level in the PC group remained elevated. This was because of their high levels of glycated LDL, which leads to LDL oxidation. The results suggest that a significant lag time may exist in the PC group before better glycemic control decreases sufficient amount of glycated LDL and then decreases OxLDL.

In the present study, I also documented that plasma OxLDL levels vary in circadian fashion, particularly in patients with poor glycemic control at admission. The OxLDL level in both the MC and PC groups together was more than $10 \%$ higher in the daytime than at night $(\mathrm{p}=0.02)$. In the MC group, OxLDL levels were unchanged all day. In the PC group, OxLDL levels were significantly higher in the morning. There is no other report about the daily variation in OxLDL levels of diabetics, but in five normal control patients consuming a regular diet had a series of OxLDL measurements, and it was reported that the OxLDL level was unchanged all day [17]. These results show that plasma OxLDL level did not change all day when the glycated HbA1c level was under $9.0 \%$. It has been reported that in six well-trained runners who ran continuously for four hours, LDL susceptibility to oxidation was increased significantly after running [22]. Changes in LDL susceptibility to oxidation could help explain why there is circadian variation and why the highest OxLDL level of the day occurred in the morning in patients with poor glycemic control at admission. Increased activity after getting up in the morning may be related to a morning rise of oxidized LDL. The presence of a morning peak in OxLDL may be associated with an increase in rates of acute myocardial infarction [28] and ischemic stroke [29].

My data also indicates that plasma OxLDL in diabetic patients is higher than that in non-diabetic patients, although this did not reach statistical significance, partly because of the sample size. My results are consistent with the report of Toshima et al. indicating a significant increase in plasma OxLDL in diabetics [16]. Yoshida et al. have shown increased susceptibility of LDL to in vitro oxidation in diabetics [30] and this is consistent with the demonstration 
of increased susceptibility to oxidation of glycated LDL [8]. However, there were two reports indicating no increase in OxLDL in diabetics $[31,32]$. A potential explanation for these discrepant results lies in my demonstration that moderate glycemic control clearly reduces OxLDL levels in diabetics.

My results suggest that levels of glycated LDL may be an important agent of proatherogeneric stimuli in the diabetic group, since in the PC group better glycemic control during a mean hospital stay of 19 days was not sufficiently long to be reflected in a reduction of OxLDL.

I conclude that plasma OxLDL in diabetic patients is higher than that in non-diabetic patients and has a circadian variation in patients with poor glycemic control at admission. Plasma OxLDL is decreased by glycemic control, particularly in patients with moderate glycemic control at admission. Long-term glycemic control could reduce the progression of atherosclerosis by reducing OxLDL levels.

\section{Acknowledgements}

I gratefully thank Mr. Junji Kimura and Ms. Kyoko Shimamura, Vessel Research laboratory Co. Ltd, for their technical assistance. Parts of the work in this article were presented at the XXII Congress of the European Society of Cardiology (Amsterdam, 2000).

\section{References}

[1] "Epidemiology of Diabetes Interventions and Complications (EDIC) Design, implementation, and preliminary results of a long-term follow-up of the Diabetes Control and Complications Trial cohort," Diabetes Care 22:99-111, 1999

[2] K.T. Khaw, N. Wareham, R. Luben, S. Bingham, S. Oakes, et al., "Glycated haemoglobin, diabetes, and mortality in men in Norfolk cohort of european prospective investigation of cancer and nutrition (EPIC-Norfolk)," BMJ 322:15-18, 2001

[3] A.I. Adler, H.A. Neil, S.E. Manley, R.R. Holman, and R.C. Turner, "Hyperglycemia and hyperinsulinemia at diagnosis of diabetes and their association with subsequent cardiovascular disease in the United Kingdom prospective diabetes study (UKPDS 47)," Am Heart J 138:S353-S359, 1999

[4] E. Schleicher, T. Deufel, and O.H. Wieland,"Non-enzymatic glycosylation of human serum lipoproteins. Elevated epsilon-lysine glycosylated low density lipoprotein in diabetic patients," FEBS Lett 129:1-4, 1981

[5] E.C. Tsai, I.B. Hirsch, J.D. Brunzell, and A. Chait, "Reduced plasma peroxyl radical trapping capacity and increased susceptibility of LDL to oxidation in poorly controlled IDDM," Diabetes 43:1010-1014, 1996

[6] K. Kobayashi, J. Watanabe, F. Umeda, and H. Nawata, "Glycation accelerates the oxidation of low density lipoprotein by copper ions," Endocr J 42:461-465, 1995

[7] A. Bowie, D. Owens, P. Collins, A. Johnson, and G.H. Tomkin, "Glycosylated low density lipoprotein is more sensitive to oxidation: implications for the diabetic patient?," Atherosclerosis 102:63-67, 1993

[8] G. Sobal, J. Menzel, and H. Sinzinger, "Why is glycated LDL more sensitive to oxidation than native LDL? A comparative study," Prostaglandins Leukot Essent Fatty Acids. 63:177-86, 2000

[9] S. Parthasarathy, N. Santanam, S. Ramachandran, and O. Meilhac, "Oxidants and antioxidants in atherogenesis: an appraisal,” J. Lipid Res. 40: 2143 - 2157, 1999

[10] S. Parthasarathy, and S.M. Rankin, "Role of oxidized low density lipoprotein in atherogenesis," Prog Lipid Res. 31:127-143, 1992

[11] Y. Higashi, T. Peng, J. Du, S. Sukhanov, Y. Li, et al., "A redox-sensitive pathway mediates oxidized LDL-induced downregulation of insulin-like growth factor-1 receptor" J. Lipid Res. 46:1266-1277, 2005

[12] S. Sukhanov, and P. Delafontaine, "Protein chip-based microarray profiling of oxidized low density lipoprotein-treated cells," Proteomics 5:1274-1280, 2005

[13] S. Sukhanov, Y.H. Song, and P. Delafontaine, "Global analysis of differentially expressed genes in oxidized LDL-treated human aortic smooth muscle cells," Biochem. Biophys. Res. Commun. 306:443-449, 2003

[14] Y. Li, Y. Higashi, H. Itabe, Y.H. Song, J. Du, et al., "Insulin-Like Growth Factor-1 Receptor Activation Inhibits Oxidized LDL-Induced Cytochrome C Release and Apoptosis via the Phosphatidylinositol 3 Kinase/Akt Signaling Pathway" Arterioscler Thromb Vasc Biol 23: 2178-2184, 2003

[15] World Medical Association Declaration of Helsinki, "Recommendations guiding physicians in biomedical research involving human subjects," Cardiovasc Res 35:2-3, 1997

[16] S. Toshima, A. Hasegawa, M. Kurabayashi, H. Itabe, T. Takano, et al., "Circulating oxidized low density lipoprotein levels. A biochemical risk marker for coronary heart disease," Arterioscler Thromb Vasc Biol 20:2243-2247, 2000

[17] H. Kohno, N. Sueshige, K. Oguri, H. Izumidate, T. Masunari, et al., "Simple and practical sandwich-type enzyme immunoassay for human oxidatively modified low density lipoprotein using antioxidized phosphatidylcholine monoclonal antibody and antihuman apolipoprotein-B antibody," Clin Biochem 33:243-253, 2000

[18] T. Shoji, Y. Nishizawa, M. Fukumoto, K. Shimamura, J. Kimura, et al., "Inverse relationship between circulating oxidized low density lipoprotein (oxLDL) and anti-oxLDL antibody levels in healthy subjects," Atherosclerosis 148:171-177, 2000

[19] T.J. Lyons, R.L. Klein, J.W. Baynes, H.C. Stevenson, and M.F. Lopes-Virella, "Stimulation of cholesteryl ester synthesis in human monocyte-derived macrophages by low-density lipoproteins from type 1 (insulin-dependent) diabetic patients: the influence of non-enzymatic glycosylation of low-density lipoproteins," Diabetologia 30:916-923, 1987

[20] K. Katoh, "Possible relevance of lipid peroxidation and thromboxane production to the initiation and/or evolution of microangiopathy in non-hyperlipidemic type 2 diabetes mellitus," Diabetes Res Clin Pract 18:89-98, 1992 
[21] W.A. Oranje, G.J. Rondas-Colbers, G.N. Swennen, H. Jansen, and B. Wolffenbuttel, "Lack of effect on LDL oxidation and antioxidant status after improvement of metabolic control in type 2 diabetes," Diabetes Care 22:2083-2084, 1999

[22] J.L. Sanchez-Quesada, R. Homs-Serradesanferm, J. Serrat-Serrat, J.R. Serra-Grima, F. Gonzalez-Sastre, et al., "Increase of LDL susceptibility to oxidation occurring after intense, long duration aerobic exercise," Atherosclerosis 118:297-305, 1995

[23] T.J. Vasankari, U.M. Kujala, T.M. Vasankari, and M. Ahotupa, "Reduced oxidized LDL levels after a 10-month exercise program," Med Sci Sports Exerc 30:1496-1501, 1998

[24] G. Sobal, J.E. Menzel, and H. Sinzinger, "Do E-series prostaglandins and their metabolites influence oxidation of native and glycated low-density lipoproteins?," Prostaglandins Other Lipid Mediat 55:67-76, 1998

[25] V. Gouaze, N. Dousset, J.C. Dousset, and P. Valdiguie, "Effect of nicotine and cotinine on the susceptibility to in vitro oxidation of LDL in healthy non smokers and smokers," Clin Chim Acta 277:25-37, 1998

[26] L. Cominacini, U. Garbin, A.M. Pastorino, A. Davoli, M. Campagnola, et al., "Predisposition to LDL oxidation in patients with and without angiographically established coronary artery disease," Atherosclerosis 99:63-70, 1993
[27] E. Maggi, E. Marchesi, V. Ravetta, A. Martignoni, G. Finardi, et al., "Presence of autoantibodies against oxidatively modified low-density lipoprotein in essential hypertension: a biochemical signature of an enhanced in vivo low-density lipoprotein oxidation,” J Hypertens 13:129-138, 1995

[28] A. Hjalmarson, E.A. Gilpin, P. Nicod, H. Dittrich, H. Henning, et al. "Differing circadian patterns of symptom onset in subgroups of patients with acute myocardial infarction," Circulation 80:267-275, 1989

[29] J.R. Marler, T.R. Price, G.L. Clark, J.E. Muller, T. Robertson, et al., "Morning increase in onset of ischemic stroke," Stroke 20:473-476, 1989

[30] H. Yoshida, T. Ishikawa, and H. Nakamura, "Vitamin E/lipid peroxide ratio and susceptibility of LDL to oxidative modification in non-insulin-dependent diabetes mellitus," Arterioscler Thromb Vasc Biol 17:1438-1446, 1997

[31] S. Ehara, M. Ueda, T. Naruko, K. Haze, A. Itoh, et al., "Elevated levels of oxidized low density lipoprotein show a positive relationship with the severity of acute coronary syndromes," Circulation 103:1955-1960, 2001

[32] K. Kugiyama, S. Sugiyama, H. Soejima, H. Kawano, T. Sakamoto, et al., "Increase in plasma levels of oxidized low-density lipoproteins in patients with coronary spastic angina," Atherosclerosis 154:463-467, 2001 